\title{
Composition and structure of helminth communities in two populations of Pipistrellus pipistrellus (Chiroptera: Vespertilionidae) from Spain
}

\author{
J. Guillermo Esteban ${ }^{1}$, Blanca Amengual ${ }^{2}$ and Jordi Serra Cobo ${ }^{3}$
}

${ }^{1}$ Departamento de Parasitología, Facultad de Farmacia, Universidad de Valencia, Av. Vicente Andrés Estellés s/n, 46100
Burjassot, Valencia, Spain;
${ }^{2}$ Departamento de Biología Animal (96-SGR0072), Universidad de Barcelona, Av. Diagonal, 645, 08028 Barcelona, Spain;
${ }^{3}$ Instituto Pirenaico de Ecología (CSIC), Av. Montañana, 177, Apdo. 202, 50080 Zaragoza, Spain

Key words: ecology, helminth community, bats, Pipistrellus pipistrellus, Spain

\begin{abstract}
The community composition and structure of helminths of Pipistrellus pipistrellus (Schreber, 1774) from two widely separated Spanish localities, El Saler $(\mathrm{n}=42)$ and the San Pedro pothole $(\mathrm{n}=34)$, were determined and compared. Five species of trematodes, Plagiorchis (Plagiorchis) sp., Lecithodendrium (Lecithodendrium) linstowi Dollfus, 1931, Prosthodendrium (Prosthodendrium) sp., Pycnoporus heteroporus (Dujardin, 1845) and Parabascus semisquamosus (Braun, 1900), and one species of cestode, Hymenolepis pipistrelli López-Neyra, 1941, were found. The two bat populations harboured the same helminth species and showed the same trematode dominance, but the most important differences between the two helminth community structures were attributable to $L$. (L.) linstowi and H. pipistrelli. The mean species richness in the two localities was not significantly different. The mean number of helminth species per infected bat, mean infracommunity abundance and mean infracommunity diversity showed significant differences between both localities. The number of helminths per bat in both populations displayed an aggregated distribution. Results indicate that the different characteristics of the $P$. pipistrellus foraging area in both localities are important in determining the composition and structure of helminth communities in this bat species. This is the first study of a Palaearctic bat helminth community.
\end{abstract}

Since the publication of Esch et al. (1990a), there has been an increasing interest in helminth communities of different vertebrate hosts, focused mainly on the identification of those factors that contribute to the organisation of helminth communities at different hierarchical levels (Esch et al. 1990b, Bush et al. 1997). In this context, the structure of helminth communities of bats is less well known.

Helminths of bats have been the subject of general reviews, checklists and keys, and numerous reports of species descriptions or new host or locality records. Nevertheless, only a few investigators (Nickel and Hansen 1967, Coggins et al. 1982, Lotz and Font 1985, 1991, 1994) have conducted ecological studies on the helminth communities of primarily American bats, despite the fact that they represent the second most species-rich mammal order and exhibit a wide geographic distribution.

The common pipistrelle, Pipistrellus pipistrellus (Schreber, 1774) (Chiroptera: Vespertilionidae), is one of the most abundant bat species of the Palaearctic region (Corbet 1978). This species lives throughout almost all of Europe and employs a large variety of roosts. In Spain it has a clear anthropophilic character, and the roosts are often found in human habitations (roofs, attics, ventilation holes, cracks of buildings, etc.). To date, the Spanish helminthfauna of the common pipistrelle comprises 11 species: 8 trematodes, 1 cestode and 2 nematodes (Botella et al. 1993).

The aim of this paper is to analyse and compare, at both component and infracommunity levels, the community composition and structure of helminths of P. pipistrellus from two Spanish localities.

\section{MATERIALS AND METHODS}

Localities and sampling. A total of $76 P$. pipistrellus adults from two localities, El Saler $(\mathrm{n}=42 ; 19$ males, 23 females) (Province of Valencia) and San Pedro pothole $(\mathrm{n}=$ 34; 18 males, 16 females) (Province of Teruel) were collected from the same place at each locality in the summer of 1993 . The distance between localities is $340 \mathrm{~km}$.

El Saler is a small town within the limits of the Albufera Park, located $10 \mathrm{~km}$ to the south of the city of Valencia. The Park comprises a freshwater lagoon $(2,837 \mathrm{ha})$ and the marshes of rice fields surrounding the lake $(12,000 \mathrm{ha})$. The climate is typically Mediterranean, with mild winters (average temperature of the coldest month: $10.5^{\circ} \mathrm{C}$ ) and long warm, rainless summers (average temperature of the warmest month: $24.5^{\circ} \mathrm{C}$ ). The average annual precipitation is $350 \mathrm{~mm}$ (Riba et al. 1980). This pipistrelle is the most abundant bat species in the Albufera Park, with an estimated population of tens of thousands of individuals (Faus 1990). All bats were captured alive from a residential building, on a random basis. 
The San Pedro pothole is in turn located in the vicinity of the Iberian mountain system (altitude $520 \mathrm{~m}$ ), near the village of Oliete. The floor is partly occupied by a lagoon with an important primary productivity that allows the proliferation of a number of consumer species (aquatic insects, snails, amphibians) (Serra-Cobo et al. 1993). The climate is semiarid, with cold winters (average temperature of the coldest month: $5^{\circ} \mathrm{C}$ ) and warm and dry summers (average temperature of the warmest month: $25^{\circ} \mathrm{C}$ ). The average annual precipitation is $350-400 \mathrm{~mm}$. The estimated population of this bat species is several hundred individuals (Serra-Cobo et al. 1993). The bats were captured alive with a mist net and on a random basis, upon emerging from the pothole.

Parasitological procedures and helminth community measurements. Bats were transported in boxes to the work place within $5 \mathrm{hr}$ of collection, killed and the body cavity opened. The gastrointestinal tract was removed by cutting across the oesophagus and rectum. Each organ was examined separately under a dissecting microscope. Cestodes were fixed in hot $70 \%$ ethanol and preserved in $70 \%$ ethanol, and trematodes first in Bouin's solution between slide and coverslip and then in $70 \%$ ethanol. Platyhelminths were mounted in toto with Canada balsam after staining with Grenacher boracic carmine for trematodes or chlorhydric carmine for cestodes. The helminths were identified and the number of individuals of each species from each helminth infracommunity was recorded. Voucher material is deposited in the helminthological collection of the Department of Parasitology, Faculty of Pharmacy, University of Valencia (Valencia, Spain).

Analyses of helminth community structure were carried out at both component and infracommunity levels (Holmes and Price 1986, Pence 1990). Quantitative descriptors of parasite populations and ecological terms are in accordance with Bush et al. (1997). We distinguished between common species (prevalence $\geq 10 \%$; = component species sensu Bush et al. 1990 ) and rare species (prevalence $<10 \%$ ). Measures of component community structure were the total number of helminths and helminth species. Measures of infracommunity structure were the mean number of helminths and species of helminths, and the mean Brillouin's index per bat (infected and uninfected) and for infected bats only. Cumulative host versus cumulative helminth species curves were generated by selecting hosts at random from our sample and scoring the accumulation of helminth species (Lotz and Font 1985). The procedure was repeated ten times for each sample of hosts.

Statistical procedures. The chi square test with Yates' correction for continuity was performed, or Fisher's exact test (Sokal and Rohlf 1981, Siegel 1985), where appropriate, for comparison purposes. Normally distributed data were analysed by the Student t-test. The Mann-Whitney U-test was used for non-normally distributed data. A KolmogorovSmirnov test was performed to compare observed and expected distributions (Siegel 1985). Aggregated distributions were analysed by the estimate of the k-parameter, the fitting to a negative binomial distribution and the comparison between observed and expected frequencies by the chi-square test (Bliss and Fisher 1953).

\section{RESULTS}

Five species of trematodes, Plagiorchis (Plagiorchis) sp. (Plagiorchiidae), Lecithodendrium (Lecithodendrium) linstowi Dollfus, 1931, Prosthodendrium (Prosthodendrium) sp., Pycnoporus heteroporus (Dujardin, 1845) and Parabascus semisquamosus (Braun, 1900) (Lecithodendriidae), and one species of cestode, Hymenolepis pipistrelli López-Neyra, 1941 (Hymenolepididae), all from intestinal sites, were found in the two bat populations. Summary data on the composition of the helminth component communities are presented in Table 1. Both communities harboured the same helminth species, though the patterns were distinct. El Saler showed a significantly greater prevalence (Fisher test, $\mathrm{p}=0.002)$, mean intensity $(\mathrm{U}=232.5, \mathrm{p}<0.001)$ and mean abundance $(\mathrm{t}=4.84, \mathrm{p}<0.001)$ for total trematodes than San Pedro. Moreover, significant differences in the mean intensity of $L$. (L.) linstowi ( $\mathrm{U}=$ 141.5, $\mathrm{p}<0.001)$ and Prosthodendrium $(P$.$) sp. (\mathrm{U}=$ $29, \mathrm{p}<0.01$ ), and in mean abundance of $L$. (L.) linstowi $(\mathrm{t}=5.4, \mathrm{p}<0.001)$, were detected between both localities (the values being greater for El Saler). Nevertheless, the data for cestodes were significantly different, the prevalence (chi-square $=22.9, \mathrm{p}<0.001)$ and mean abundance of $H$. pipistrelli $(\mathrm{t}=4.9, \mathrm{p}<0.001)$ being greater in San Pedro.

The two communities were dominated by trematodes. Whereas in El Saler three species $[L$. $(L$. $)$ linstowi, Prosthodendrium (P.) sp. and Plagiorchis (P.) sp.] were classified as common species, in San Pedro the figure increased to four with the addition of $H$. pipistrelli, which was the second most prevalent species. No significant differences were noted in the results obtained between male and female hosts ( $\mathrm{p}>$ $0.05)$.

Helminth infracommunity structure of the two bat populations is presented in Table 2. Only six common pipistrelles from San Pedro were not parasitised, the remainder harboured between one and five helminth species. The difference in mean species richness between both localities $(1.4 \pm 0.7$ for El Saler; $2.0 \pm 1.4$ for San Pedro) was not statistically significant $(\mathrm{t}=1.4$, $p>0.1)$. Nevertheless, the pattern of helminth infection of bats from El Saler exhibited a significantly different Poisson distribution (Kolmogorov-Smirnov test, p < 0.001 ), with a greater frequency of single infections, while the pattern in San Pedro corresponded to a Poisson distribution (Kolmogorov-Smirnov test, $\mathrm{p}>$ $0.05)$ with a greater frequency of single and triple infections (Fig. 1). An analysis of the cumulative host versus cumulative helminth species curves (Fig. 2) showed that recovery of over $90 \%$ of the species required the examination of 32 bats in El Saler versus 14 bats in San Pedro.

The mean number of helminth species per infected bat was significantly greater in San Pedro than in El Saler $(\mathrm{t}=4.24, \mathrm{p}<0.001)$, and the mean infracommunity abundance showed significant differences $(\mathrm{t}=$ 4.6, $\mathrm{p}<0.001)$. 
Table 1. Quantitative descriptors of infection of helminth species collected from Pipistrellus pipistrellus in the two Spanish localities.

\begin{tabular}{|c|c|c|c|c|c|c|c|c|}
\hline \multirow[t]{2}{*}{ Helminth species } & \multicolumn{4}{|c|}{$\begin{array}{c}\text { El Saler } \\
\mathrm{n}=42\end{array}$} & \multicolumn{4}{|c|}{$\begin{array}{c}\text { San Pedro } \\
\mathrm{n}=34\end{array}$} \\
\hline & No. $\mathrm{H}$ & $\mathrm{P} \%$ & $\mathrm{MI} \pm \mathrm{SD}(\mathrm{r})$ & $\mathrm{MA} \pm \mathrm{SD}$ & No. $\mathrm{H}$ & $\mathrm{P} \%$ & $\mathrm{MI} \pm \mathrm{SD}(\mathrm{r})$ & $\mathrm{MA} \pm \mathrm{SD}$ \\
\hline TREMATODA & 1232 & 100 & $29.3 \pm 26.0(1-115)$ & $29.3 \pm 26.0$ & 238 & 79 & $8.8 \pm 7.3(1-32)$ & $7.0 \pm 7.4$ \\
\hline Plagiorchis (P.) sp. & 10 & 17 & $1.4 \pm 0.8(1-3)$ & $0.2 \pm 0.6$ & 6 & 15 & $1.2 \pm 0.5(1-2)$ & $0.2 \pm 0.5$ \\
\hline Lecithodendrium (L.) linstowi & 1188 & 93 & $30.5 \pm 25.4(2-112)$ & $28.3 \pm 25.7$ & 203 & 76 & $7.8 \pm 6.6(1-30)$ & $5.9 \pm 6.7$ \\
\hline Prosthodendrium (P.) sp. & 31 & 24 & $3.1 \pm 1.7(1-7)$ & $0.7 \pm 1.6$ & 25 & 38 & $1.9 \pm 2.2(1-9)$ & $0.7 \pm 1.6$ \\
\hline Pycnoporus heteroporus & 2 & 5 & $1.0 \pm 0.0(1)$ & $0.05 \pm 0.2$ & 1 & 3 & $1.0 \pm 0.0(1)$ & $0.03 \pm 0.2$ \\
\hline Parabascus semisquamosus & 1 & 2 & $1.0 \pm 0.0(1)$ & $0.02 \pm 0.2$ & 3 & 9 & $1.0 \pm 0.0(1)$ & $0.09 \pm 0.3$ \\
\hline CESTODA & 1 & 2 & $1.0 \pm 0.0(1)$ & $0.02 \pm 0.2$ & 38 & 53 & $2.1 \pm 1.3(1-4)$ & $1.1 \pm 1.4$ \\
\hline Hymenolepis pipistrelli & 1 & 2 & $1.0 \pm 0.0(1)$ & $0.02 \pm 0.2$ & 38 & 53 & $2.1 \pm 1.3(1-4)$ & $1.1 \pm 1.4$ \\
\hline TOTAL & 1233 & 100 & $29.3 \pm 26.0(1-115)$ & $29.3 \pm 26.0$ & 276 & 82 & $9.9 \pm 7.4(1-32)$ & $8.1 \pm 7.7$ \\
\hline
\end{tabular}

$\mathrm{n}$ - sample size, No. $\mathrm{H}$ - number of helminths, $\mathrm{P} \%$ - prevalence, $\mathrm{MI} \pm \mathrm{SD}(\mathrm{r})$ - mean intensity (range), $\mathrm{MA} \pm \mathrm{SD}$ - mean abundance

Table 2. Characteristics of the helminth infracommunities of Pipistrellus pipistrellus from the two Spanish localities.

\begin{tabular}{|l|c|c|}
\hline & El Saler & San Pedro \\
\hline No. bats examined & 42 & 34 \\
No. infected bats & 42 & 28 \\
Mean No. helminths/infected bat \pm SD & $29.4 \pm 26.0$ & $9.9 \pm 7.4$ \\
Mean No. helminth species/infected bat \pm SD & $1.4 \pm 0.7$ & $2.4 \pm 1.2$ \\
Mean No. helminths/host individual \pm SD & $29.4 \pm 26.0$ & $8.1 \pm 7.7$ \\
Mean No. helminth species/host individual \pm SD & $1.4 \pm 0.7$ & $2.0 \pm 1.4$ \\
Mean Brillouin's index/infected bat \pm SD & $0.1 \pm 0.2$ & $0.6 \pm 0.4$ \\
Mean Brillouin's index/host individual \pm SD & $0.1 \pm 0.2$ & $0.5 \pm 0.4$ \\
Brillouin's index range & $0-0.7$ & $0-1.4$ \\
\hline
\end{tabular}


El Saler

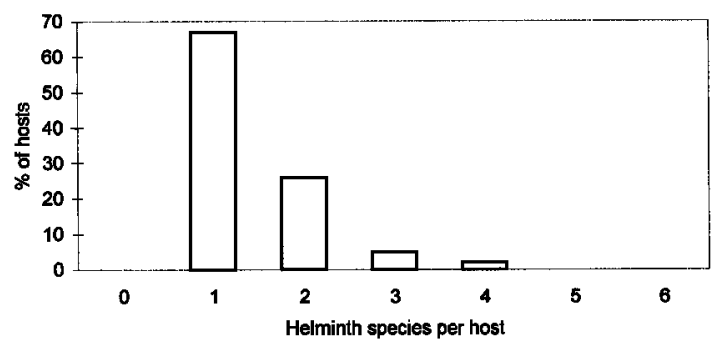

San Pedro

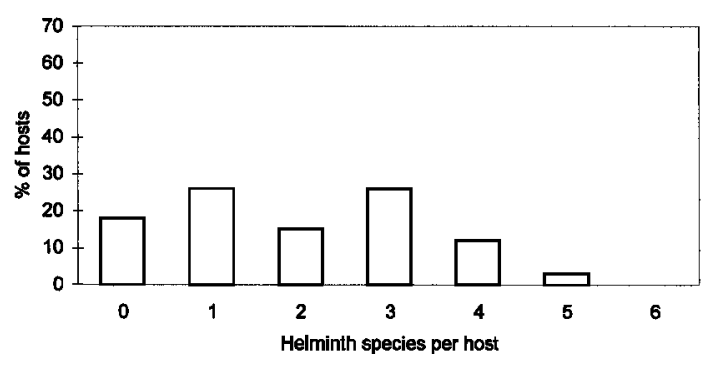

Fig. 1. Frequency histograms of the number of helminth species per host in both localities.
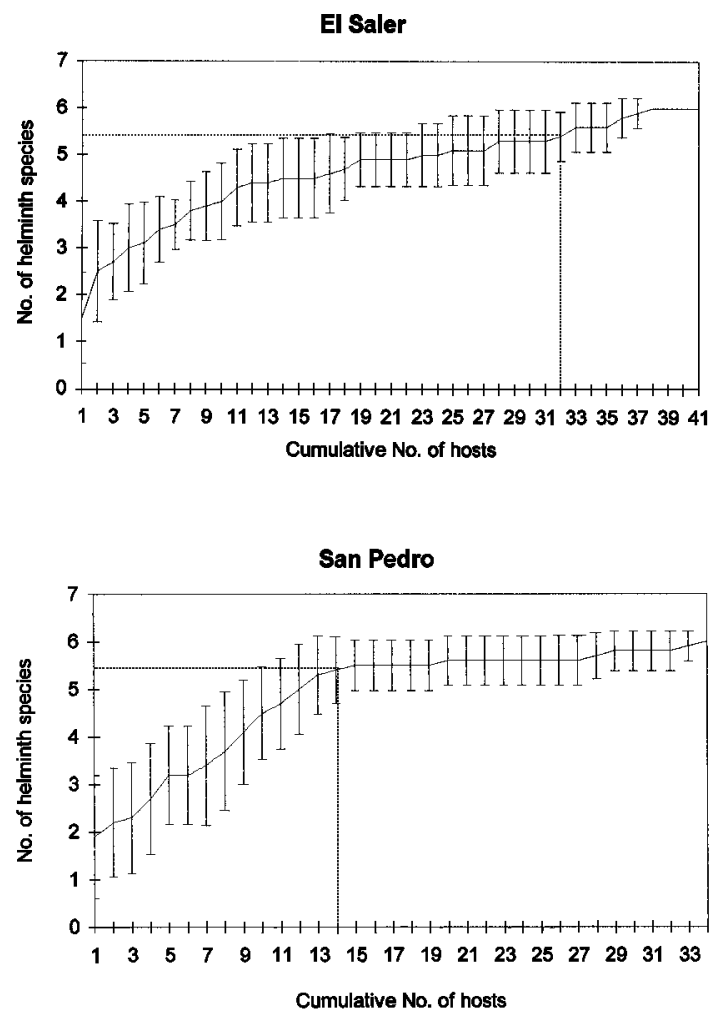

Fig. 2. Graph of the accumulation of helminth species versus the number of hosts examined. Vertical solid lines represent the range of species from the ten randomisations.
El Saler

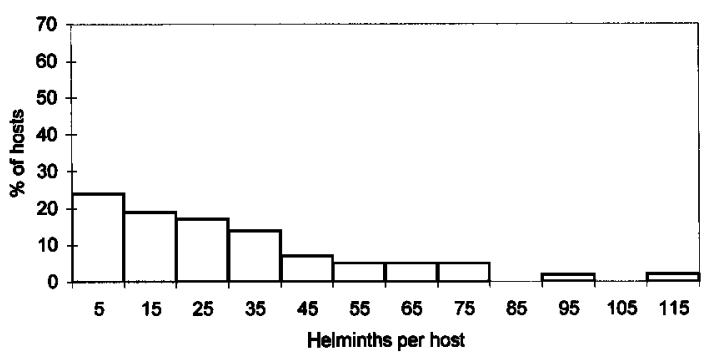

San Pedro

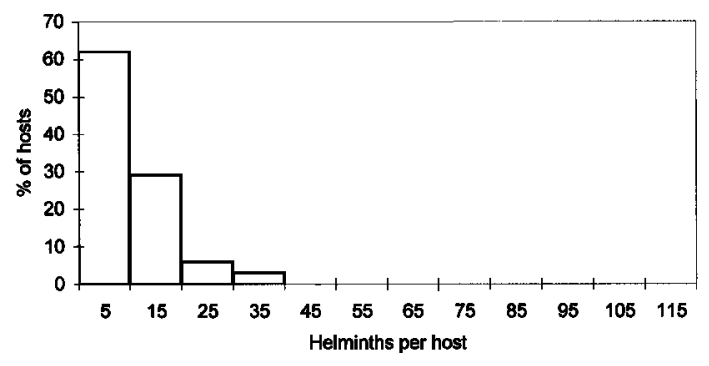

Fig. 3. Frequency histograms of the number of helminths per host in both localities.

The frequency distributions of the number of helminths per host in each bat population (Fig. 3) fitted a negative binomial distribution $(\mathrm{k}=1.3601$ in $\mathrm{El}$ Saler; $\mathrm{k}=0.5326$ in San Pedro). The comparison between observed and expected frequencies indicates a good agreement with the negative binomial (chi-square $=6.380, \mathrm{p}>0.5$ for El Saler; chi-square $=4.507, \mathrm{p}>$ 0.1 for San Pedro). Infracommunity diversity (Brillouin's index) was significantly higher in San Pedro than in El Saler $(\mathrm{U}=282, \mathrm{p}<0.001)$, and it remained higher even when values were calculated using data from infected and uninfected bats $(\mathrm{U}=450$, $\mathrm{p}<0.01)$.

\section{DISCUSSION}

Few authors have presented data on bat helminth communities (Coggins 1988, Lotz and Font 1985, 1991, 1994), and the published data are focused on American bats. In this sense, bats in general have been neglected as topics for study in parasite ecology.

We considered the helminth species collected from the same bat species, in the same time period, and corresponding to two localities sufficiently far apart to discard contact between the two populations. This ensured that the results obtained in the helminth commu-nities were real and not artifacts of sampling or proce-dure.

The two bat populations harboured the same six helminth species and showed the same trematode dominance. Nevertheless, the most significant differences between the two helminth community structures are 
referred to Lecithodendrium (L.) linstowi and Hymenolepis pipistrelli. The former is the most relevant common species of both communities, while $H$. pipistrelli is a common species only in San Pedro.

The significant differences observed in terms of infra-community abundance and diversity in both Pipistrellus pipistrellus populations are also attributable to the two above mentioned species. El Saler presents the fewest helminth species per infected bat and the least diversity, due to the higher proportion of bats harbouring a single helminth species, $L$. (L.) linstowi, as well as to the higher abundance of this species. In this sense, the greater helminth diversity of San Pedro is consistent with the cumulative species-host curves, which would explain why fewer bats were required to ensure collec-tion of $90 \%$ of the helminth species.

The number of helminths per bat follows a negative binomial distribution in both bat populations, thus indicating an aggregated distribution. Most of the bats tend to harbour few helminths, while a minority harboured the largest proportion of the helminth population.

Several factors can influence helminth community structure. Concerning the host species, the common pipistrelle is an endotherm species that may be characterised by the simplicity of the digestive tract, a low vagility within this host group, and its non-selective feeding habits, with the consequent possibility of access to a relatively wider range of prey that act as intermediate host for different helminths. In this sense, all the helminth species detected are heteroxenous, with different specificities toward the definitive host. The life cycles that have been elucidated in congeneric species of the trematode species found in this study (McMullen 1937, Macy 1960, Williams 1967) are aquatic triheteroxenous. The finding of these same species, basically the generalist species $L$. (L.) linstowi, parasitising a wide range of bat species from the same localities (Esteban, unpubl.) is suggestive of scant specificity toward the definitive host. In contrast, the only cestode species detected, $H$. pipistrelli, can be expected to exhibit a terrestrial diheteroxenous cycle. The features known thus far only for P. pipistrellus (Esteban et al. 1990, 1991, Botella et al. 1993) allow us to presume an oioxenous specificity toward the common pipistrelle.
The different characteristics of the $P$. pipistrellus foraging area in both localities are one relevant feature to understand our data. The existence of aquatic and terrestrial habitats in both localities explains the same helminth community richness. Nevertheless, the proportion of surface area covered by water differs between the two localities. El Saler exhibits a clear dominance of aquatic habitats, and is thus more likely to harbour helminths with aquatic life cycles. In contrast, San Pedro has a clear dominance of terrestrial over aquatic environments; this would in turn favour the increased viability of terrestrial life cycles. Moreover, it should be pointed out that $P$. pipistrellus in El Saler is active practically throughout the year, due to the mild climatic conditions, and the greatest feeding activity of this bat species was observed on the lagoon and rice fields. In contrast, the harsh environmental conditions found in San Pedro cause this bat species to show scant activity in the coldest months (December-February), and the greatest feeding activity was observed in terrestrial habitats (Serra, unpubl.).

As the first study of a Palaearctic bat parasite community, the present work constitutes the basis for future studies of possible interspecific interactions that may allow us to elucidate the helminth community patterns in this particular host group.

Acknowledgements. The present study was supported by Spanish DGICYT Project PB96-0401-C02-02 of Ministerio de Educación y Cultura, Madrid, and by Project 26.08.P.41 3D.227.07 of Ministerio de Sanidad y Consumo, Madrid. The authors thank to the Direcció General de Política Forestal y Pesquera and to the Dirección General de Conservación del Medio Natural de la Consejeria del Medio Ambiente de la Generalitat Valenciana (Valencia, Spain), as well as to the Dirección General del Medio Natural de la Diputación General de Aragón (Zaragoza, Spain), for the official licences (Generalitat Valenciana: letter of May 28, 1993; Diputación General de Aragón: letter of December 23, 1992) to collect bats in the field. Thanks are also due to Dr. P. Botella, Dr. R. Toledo, Lic. C. Fuentes and Lic. L. Sánchez (Valencia, Spain) for their technical collaboration in the field work, and Dr. J.P. Martínez-Rica (Zaragoza, Spain) for his collaboration in statistical analyses.

\section{REFERENCES}

BLISS C.I., FISHER R.A. 1953: Fitting the negative binomial distribution to biological data. Note on the efficient fitting of the negative binomial. Biometrics 9: 176-200.

BOTELLA P., SANCHEZ L., ESTEBAN J.G. 1993: Helminthfauna of bats in Spain. III. Parasites of Pipistrellus pipistrellus (Schreber, 1774) (Chiroptera: Vespertilionidae). Res. Rev. Parasitol. 53: 63-70.

BUSH A.O., AHO J.M., KENNEDY C.R. 1990: Ecological versus phylogenetic determinants of helminth parasite community richness. Evol. Ecol. 4: 1-20.
BUSH A.O., LAFFERTY K.D., LOTZ J.M., SHOSTAK A.W. 1997: Parasitology meets ecology on its own terms: Margolis et al. revisited. J. Parasitol. 83: 575-583.

COGGINS J.R. 1988: Methods for the ecological study of bat endoparasites. In: T.H. Kunz (Ed.), Ecological and Behavioral Methods for the Study of Bats. Smithsonian Institution Press, Washington, U.S.A., pp. 475-489.

COGGINS J.R., TEDESCO J.L., RUPPRECHT C.E. 1982: Seasonal changes and overwintering of parasites in the bat, Myotis lucifugus (Le Conte), in a Wisconsin hibernaculum. Am. Midl. Nat. 107: 305-315. 
CORBET G.B. 1978: The Mammals of the Palaearctic region: a Taxonomic Review. British Museum, London, U.K., $214 \mathrm{pp}$.

ESCH G.W., BUSH A.O., AHO J.M. 1990a: Parasite Communities: Patterns and Processes. Chapman and Hall, London, U.K., 335 pp.

ESCH G.W., SHOSTAK A.W., MARCOGLIESE D.J., GOATER T.M. 1990b: Patterns and processes in helminth communities: an overview. In: G.W. Esch, A.O. Bush and J.M. Aho (Eds.), Parasite Communities: Patterns and Processes. Chapman and Hall, London, U.K., pp. 1-19.

ESTEBAN J.G., OLTRA-FERRERO J.L., BOTELLA P., MAS-COMA S. 1991: Helmintos de quirópteros en España: espectro faunístico e interés aplicado de su estudio. In: J. Benzal and O. de Paz (Eds.), Los Murciélagos de España y Portugal. ICONA, Ministerio de Agricultura, Pesca y Alimentación, Colección Técnica, Madrid, España, pp. 280-304.

ESTEBAN J.G., OLTRA-FERRERO J.L., MAS-COMA S. 1990: Helmintofauna de los murciélagos de España. II. Parásitos de Miniopterus schreibersii (Kuhl, 1819) (Chiroptera: Vespertilionidae). Rev. Ibér. Parasitol. 50: 199-209.

FAUS F.V. 1990: Los mamíferos de l'Albufera de Valencia: datos preliminares. Medi Natural, Generalitat Valenciana, Valencia, España, 2: 113-128.

HOLMES J.C., PRICE P.W. 1986: Communities of parasites. In: J. Kikkawa and D.J. Anderson (Eds.), Community Ecology: Pattern and Process. Blackwell Scientific Publications, Oxford, U.K., pp. 187-213.

LOTZ J.M., FONT W.F. 1985: Structure of enteric helminth communities in two populations of Eptesicus fuscus (Chiroptera). Can. J. Zool. 63: 2969-2978.

LOTZ J.M., FONT W.F. 1991: The role of positive and negative interspecific associations in the organization of communities of intestinal helminths of bats. Parasitology 103: $127-138$.
LOTZ J.M., FONT W.F. 1994: Excess positive associations in communities of intestinal helminths of bats: a refined null hypothesis and a test of the facilitation hypothesis. J. Parasitol. 80: 398-413.

MACY R.W. 1960: The life cycle of Plagiorchis vespertilionis parorchis, n. ssp. (Trematoda: Plagiorchiidae), and observations on the effects of light on the emergence of the cercaria. J. Parasitol. 46: 337-345.

McMULLEN D.B. 1937: The life histories of three trematodes, parasites in birds and mammals, belonging to the genus Plagiorchis. J. Parasitol. 23: 235-243.

NICKEL P.A., HANSEN M.F. 1967: Helminths of bats collected in Kansas, Nebraska, and Oklahoma. Am. Midl. Nat. 78: 481-486.

PENCE D.B. 1990: Helminth community of mammalian hosts: concepts at the infracommunity, component and compound community levels. In: G.W. Esch, A.O. Bush and J.M. Aho (Eds.), Parasite Communities: Patterns and Processes. Chapman and Hall, London, U.K., pp. 230-260.

RIBA O., de BOLOS O., PANAREDA J.M., NUET J., GOSALBEZ J. 1980: Geografia física dels Països Catalans. Ketres, Barcelona, España, 226 pp.

SERRA-COBO J., BARBAULT R., ESTRADA-PEÑA A. 1993: Le gouffre de San Pedro de los Griegos (Oliete, Teruel, Espagne): un refuge de biodiversité sans équivalent en Europe. Rev. Ecol. (Terre Vie) 48: 341-348.

SIEGEL S. 1985: Estadística no Paramétrica Aplicada a las Ciencias de la Conducta. 9th ed. Trillas, México D.F., México, 344 pp.

SOKAL R.R., ROHLF F.J. 1981: Biometry. The Principles and Practice of Statistics in Biological Research. 2nd ed. W.H. Freeman and Company, New York, 859 pp.

WILLIAMS R.R. 1967: Metacercariae of Prosthodendrium naviculum Macy, 1936 (Trematoda: Lecithodendriidae) from the crayfish, Orconectes rusticus (Girard). Proc. Penn. Acad. Sci. 41: 38-41. 